\title{
Escape conditioning and low-frequency whole-body vibration: The effects of frequency, amplitude, and controls for noise and activation*
}

\author{
EDWARD L. WIKE and SHARRON S. WIKE \\ University of Kansas, Lawrence, Kans. 66044
}

Seven experiments are reported on low-frequency whole-body vibration and rats' escape conditioning in a modified Skinner box. In the first three studies, conditioning was observed but was independent of frequency. In Experiment 4 the number of escape responses was directly related to vibration amplitude. Experiment 5 was a control for vibration noise and noise termination; Experiments 6 and 7 studied vibration-induced activation. Noise termination did not produce conditioning. In Experiment $6 \mathrm{Ss}$ made more responses when responding led to termination than when it did not. In Experiment 7 Ss preferred a bar which terminated vibration to one which did not.

Experiments by Hunt \& Quay (1961) and Soskin (1963), which were designed to test Hebb's discrepancy-arousal hypothesis of motivation, have suggested that whole-body vibration is an aversive stimulus for rats. Hunt and Quay observed that Ss without a prior history of exposure to vibration would barpress to turn off vibration. Soskin found that Ss, both with and without previous vibration experience, preferred a nonvibrating goalbox over a vibrating goalbox in U-maze tests. The former investigators used $1,000-\mathrm{Hz}$ vibration of unknown amplitude, ${ }^{1}$ while the latter imposed $60 \mathrm{~Hz}$ with an average amplitude of 369.5 microns.

The aim of the present experiments was to investigate more fully the aversiveness of low-frequency whole-body vibration for rats. More precisely, escape conditioning was studied in a modified Skinner box with a vibrating floor in which barpressing briefly terminated vertical sinusoidal vibration. In contrast to the research above, lower frequencies (e.g., 8 to $22 \mathrm{~Hz}$ ) and greater amplitudes (e.g., 0.24 in., peak-to-peak) were imposed. There were two reasons for using these vibration parameters: (1) humans exposed to such lower frequencies in buildings, automobiles, and aircraft report discomfort, and (2) Schaefer, Link, Farrar, \& Weins

*This research was supported by a NASA interdisciplinary grant to the University of Kansas, Kenneth Lenzen, principal investigator. We are indebted to Drs. Lenzen, Dean Fixsen, George Kellas, Don R. Justesen, Joseph $C$. Sharp, and George W. Swift for technical and material assistance and to Cindy Wike for doing the pilot study referred to in Experiment 6.
(1959) and Schaefer, Ulmer, \& Link (1959) have found behavioral and physiological effects with rats at lower frequencies and greater amplitudes than those used by Hunt and Quay and Soskin. The purpose of the first three studies was to investigate the effects of frequency of vibration upon escape conditioning. Although the results are described in terms of "frequency," they could be interpretable as a function of acceleration, since acceleration increases as a square of frequency when the amplitude of sinusoidal vibration is held constant.

\section{EXPERIMENT 1}

The purpose of this within-groups experiment was to determine whether or not the brief termination of different frequencies of whole-body vibration functioned as a reinforcer for barpressing.

The Ss were 12 naive female Holtzman albino rats, body weight $\mathrm{M}=241 \mathrm{~g}$, range $216.5 \cdot 258.4 \mathrm{~g}$. The Ss were housed six per cage and maintained ad lib on Purina Lab Chow and water.

\section{Apparatus}

The apparatus was a modified Gerbrands Skinner box. The vibrating floor was a 0.38 -in.-thick Plexiglas panel that was bolted in the center to a permanent magnet vibrator (Model AV-2, Agac-Derritron, Inc., Alexandria, Va. 22314). The floor was stabilized by four equally spaced 1-in.-wide elastic straps that were attached to the bottom of the floor by epoxy and to the box sides by fine wires through the grid bar holes. The vibrator was driven by a $25-\mathrm{W}$ solid state power amplifier (Model OC-25, Agac-Derritron, Inc.) and programmed by standard relay equipment. Each barpress terminated the vibration for 10 sec. Barpresses during vibration and the time-outs from vibration were recorded on separate digital counters. Procedure

The Ss were assigned randomly to a 4 by 4 balanced Latin-square design, which was replicated three times. The treatments were $0,8,16$, and $22 \mathrm{~Hz}$, and $S$ had one 20-min test daily for 4 days. In each test, a single vibration frequency was presented, and the vibration was on when $S$ was placed in the box. To achieve a constant peak-to-peak amplitude of $\sim 0.24$ in., the amplifier power setting was adjusted with frequency: $8 \mathrm{~Hz}, 2.0 \mathrm{~A}$; $16 \mathrm{~Hz}, 1.35 \mathrm{~A} ; 22 \mathrm{~Hz}, 0.8 \mathrm{~A}$. It may be noted that at constant amplitude, the power required varies indirectly with frequency.

Results

The numbers of barpresses were transformed to $\log (X+1)$, and frequency was found to have a significant effect upon barpressing (F

17.89, df $=3 / 30, p<.001) .2$ By Bonferroni $t$ tests (Wike, 1971), it was found that more responses occurred ( $\mathrm{p}<.01$ ) under vibration $(8 \mathrm{~Hz} \mathbf{M}=$ $1.1595,16 \mathrm{~Hz} \mathbf{M}=0.9777,22 \mathrm{~Hz} \mathrm{M}=$ $1.1434)$ than without vibration $(0 \mathrm{~Hz}$ $M=0.2551$ ), but the three vibration treatments did not differ reliably from one another. It was also observed that when the Ss were exposed to vibration, they exhibited "emotional" responses in the form of rapid breathing ("panting") and increased defecation and urination.

EXPERIMENT 2

There is always the danger in Latin-square designs of carryover effects and of interpreting interactions as main effects. Therefore, effects of vibration frequency were investigated further using a between-S design.

Subjects

The Ss were 20 female Holtzman albino rats, body weight $M=260.4 \mathrm{~g}$, range $241.7-282.9 \mathrm{~g}$. The $S s$ had undergone acquisition and extinction in a runway several weeks earlier and had been on ad lib feeding and watering following completion of the runway experiment.

Apparatus

The apparatus, power settings, etc. were identical to those in Experiment 1.

Procedure

The Ss were assigned randomly and equally to four frequency treatments: $0,8,16$, and $22 \mathrm{~Hz}$. Each $\mathrm{S}$ received a 20 -min test on 3 successive days. In contrast to the first experiment, the $\mathrm{S} s$ were exposed to only one level of vibration in the three tests. In this experiment and in all studies thereafter, the order of testing the $S$ s varied randomly from day to day. 
Results

The numbers of barpresses were subjected to an analysis of variance which revealed that frequency $(F=$ $50.69, \mathrm{df}=3 / 16, \mathrm{p}<.001)$ and days $(F=13.99, \mathrm{df}=2 / 32, \mathrm{p}<.001)$ were significant sources of variation. By Tukey $b$ tests it was found that the vibration groups $(8 \mathrm{~Hz} \mathrm{M}=86.6$, $16 \mathrm{~Hz} M=66.6,22 \mathrm{~Hz} M=74.9)$ made significantly more $(p<.01)$ responses than the control group $(0 \mathrm{~Hz}$ $M=1.3$ ), and that the $8-\mathrm{Hz}$ group outperformed the $16-\mathrm{Hz}$ group $(\mathrm{p}<.01)$.

\section{EXPERIMENT 3}

The previous studies consisted of 20-min exposures of rats to vibration for 3 days. This experiment involved more days of stimulation. Subjects

The 10 Ss were from the same sample as in Experiment 2 and had an average body weight of $266.3 \mathrm{~g}$, with a range of 214.5-288.4 g.

Apparatus

The apparatus was identical to that of Experiment 1.

\section{Procedure}

The Ss were assigned randomly and equally to two groups, $0-8 \mathrm{~Hz}$ and $8-8 \mathrm{~Hz}$. In the $0-8 \mathrm{~Hz}$ group during Phase 1, the Ss had no vibration for 6 days (20-min daily tests) followed by 6 days with $8 \mathrm{~Hz}$ in Phase 2 . The Ss in the $8.8 \mathrm{~Hz}$ group had $8 \mathrm{~Hz}$ in both phases. On Day 13 both groups had no vibration during a 20 -min test.

$$
\text { Results }
$$

The analysis of the numbers of barpresses in the first 12 days of testing revealed four significant sources of variation: Groups by Phases, $F=5.98, \mathrm{df}=1 / 8, \mathrm{p}<.05$ phases, $F=51.09$, df $=1 / 8, p<.001$ tests, $F=10.87$, df $=5 / 40, p<.025$ Phases by Tests, $F=10.44$, df $=5 / 40$, $p<.025$. A simple effects analysis of the Groups by Phases interaction disclosed that the $8-8-\mathrm{Hz}$ group ( $M=$ 26.0) made significantly more $(\mathrm{p}<.025)$ responses in Phase 1 than did the $0-8-\mathrm{Hz}$ group $(M=0.7)$, while in Phase 2 the groups did not differ reliably $(\mathrm{M}=54.5$ vs $\mathrm{M}=52.9$, respectively). The groups combined made significantly more $(p<.001)$ responses in Phase 2 than in Phase 1 , and, although the trend was not completely monotonic, the numbers of responses increased over tests. On Day 13, without vibration, both groups fell to the usual baseline level of performance in this apparatus ( $M=$ 4.0 and $M=3.8$, respectively).

$$
\text { DISCUSSION }
$$

The three experiments above offer substantial evidence that the brief termination of low-frequency whole-body vibration is reinforcing for barpressing. Furthermore, this phenomenon is demonstrable in both
within-S and between-S designs. With the exception of one comparison in Experiment 2, vibration acted in an all-or-none manner, that is, within the 8 - to $22-\mathrm{Hz}$ limits employed in present studies, barpressing was independent of frequency. It is possible that with a lower level of vibration, e.g., $4 \mathrm{~Hz}$, frequency might be an effective parameter, but this frequency level could not be achieved with our apparatus while at the same time obtaining an amplitude of 0.24 in.

The purposes of the following experiments were to investigate: (1) the relationship between escape conditioning and the amplitude of low-frequency whole-body vibration; (2) the role of noise perse in the vibration-escape conditioning effect; and $(3)$ the role of activation produced by vibration vs activation plus the termination of vibration in the vibration-escape conditioning effect. EXPERIMENT 4

The goal of this study was to investigate the effect of amplitude of vibration upon escape conditioning.

$$
\text { Subjects }
$$

The Ss were 21 female Holtzman albino rats, body weight $\mathrm{M}=273.2 \mathrm{~g}$, range 234.0-373.1 g. The Ss had previously undergone acquisition and extinction in a runway.

$$
\text { Apparatus }
$$

The apparatus was identical to that of Experiment 1.

\section{Procedure}

The Ss were assigned randomly and equally to three levels of amplitude: low amplitude group (power setting, $0.2 \mathrm{~A}$; vibration, just perceptible to touch); intermediate (power setting, $0.8 \mathrm{~A} ; \sim 0.12$ in., peak-to-peak ); and high (power setting, $2.0 \mathrm{~A} ; \sim 0.24 \mathrm{in}$.). All Ss had $8-\mathrm{Hz}$ vibration and received 20-min tests daily for 3 days.

$$
\text { Results }
$$

An analysis of variance of the numbers of barpresses yielded three significant sources of variation: amplitude $(F=33.91, \mathrm{df}=2 / 18$, $\mathrm{p}<.001)$; days $(\mathrm{F}=10.35, \mathrm{df}=2 / 36$, $\mathrm{p}<.001$ ); and Amplitude by Days ( $\mathrm{F}$ $=6.75, \mathrm{df}=4 / 36, \mathrm{p}<.001)$. On the average, over days, the numbers of barpresses increased directly with amplitude: low amplitude group, $\mathrm{M}=$ 2.7 ; intermediate, $M=23.3$; and high, $M=72.6$. Averaged over groups, the numbers of barpresses increased over days: Day $1, \mathrm{M}=23.5 ;$ Day $2, \mathrm{M}=$ 36.9; and Day $3, M=38.2$. By simple effects tests, the amplitude groups were found to be significantly different $(p<.001)$ on all days, with the differences between the groups increasing on Days 2 and 3. On Day 1, the comparison between the low amplitude group $(M=4.1)$ and high $(M=48.6)$ and between the intermediate $(M=17.7)$ and high was significant ( $\mathrm{p}<.01)$, while the low and intermediate was not $(p>.05)$. On Day 2, the comparison between the low $(M=1.3)$ and high $(M=83.1)$ and between the intermediate ( $\mathrm{M}=$ 26.1) and high was significant ( $p<.01$ ), as was that between low and intermediate $(p<.05)$. The same comparisons were reliable at the same levels of significance on Day 3: low (M $=2.7)$, intermediate $(M=26.0)$, and high $(M=86.0)$.

\section{EXPERIMENT 5}

Apparatuses producing vibration emit noise. Although no behavioral differences were observed in escape conditioning with and without a window-unit air-conditioner in operation, the possibility existed that the noise from vibration and noise termination following barpressing might be, in part, responsible for the observed escape conditioning. The purpose of Experiment 5 was to investigate this possibility.

$$
\text { Subjects }
$$

The Ss were 10 female Holtzman albino rats, approximately 80 days of age. The Ss had been used before in a runway study.

\section{Apparatus}

A tape recording was made of the apparatus from Experiment 1 while it was in operation $(8 \mathrm{~Hz}, 2.0 \mathrm{~A}$, $\sim 0.24$ in.).

The Ss were assigned randomly and equally to a noise and to a no-noise group. Each $S$ had a single 20 -min test in the Skinner box without vibration. The Ss in the noise group were exposed to the noise from the tape recording, and each barpress terminated the noise for $10 \mathrm{sec}$. The intensity of the noise was judged by two Os to be equal to that evoked by the actual operation of the vibrator. The Ss in the no-noise group had neither vibration nor noise. Thus, they were equivalent to the $0-\mathrm{Hz}$ control treatments in the previous studies.

\section{Results}

The numbers of responses did not differ significantly $(p>.05)$ in the noise and no-noise groups (Ms $=3.6$ and 2.6, respectively). Furthermore, both groups' barpressing was comparable to the baseline performance observed in earlier investigations.

\section{EXPERIMENT 6}

The last two experiments were the outcome of an observation from a pilot study upon the effects of vibration on consummatory behavior. Rats were exposed to continuous vibration for $20 \mathrm{~min}$ in the Skinner box, following which their intake of water was measured. To our surprise and consternation, some of the rats made a considerable number of barpresses during the vibration stimulation without its being 
terminated. Replications with other Ss exposed to continuous vibration confirmed these initial observations. Accordingly, it became mandatory to perform additional studies to clarify the role of activation resulting from continuous vibration vs the activating effect of vibration plus the reinforcing effect of the termination of vibration upon barpressing.

Subjects

The Ss were 24 female Holtzman albino rats, body weight $\mathrm{M}=258.4 \mathrm{~g}$, range $228.2-334.4 \mathrm{~g}$. The Ss had been in a runway experiment earlier. Apparatus

The apparatus was identical to that used in Experiment 1.

Procedure

The Ss were assigned randomly and equally to the cells of a 3 by 2 factorial design. The first factor was vibration frequency: $8 \mathrm{~Hz}(0.8 \mathrm{~A})$, $16 \mathrm{~Hz}(1.35 \mathrm{~A})$, and $22 \mathrm{~Hz}(2.0 \mathrm{~A})$. In each frequency, the amplitude of vibration was $\sim 0.24$ in., peak-to-peak. The second factor was vibration termination vs no termination. In the former treatment, each barpress shut off the vibration for $10 \mathrm{sec}$, as in the prior studies; in the latter treatment, barpresses had no influence on the vibration. All Ss received $20-\mathrm{min}$ tests daily for 3 days.

\section{Results}

In the experiments reported so far, the behavioral measure was always the number of barpresses which terminated the vibration. Although counts were taken of the responses emitted during the periods when the vibration was off as a consequence of barpressing, these time-out responses were not included in the analyses. ${ }^{3}$ With constant test periods of $20 \mathrm{~min}$, it was necessary to employ the total number of barpresses, i.e., presses which terminated vibration and presses during the time-outs from vibration, to secure a response measure which was comparable for the vibration termination and no-termination groups.

An analysis of variance of the total numbers of responses disclosed three significant effects: vibration termination $(\mathrm{F}=31.65, \mathrm{df}=1 / 18$, $\mathrm{p}<.001)$; days $(\mathrm{F}=9.49$, df $=2 / 36$, $\mathrm{p}<.001)$; and Termination by Days $(F=6.55, \mathrm{df}=4 / 36, \mathrm{p}<.001)$. The Ss with termination made more barpresses $(M=121.1)$ than did those without termination $(\mathrm{M}=53.7)$, number of presses increased over Days 1 and $2(\mathrm{Ms}=68.8,97.2)$, and the differences between the termination and no-termination groups increased over days: Day $1(\mathrm{M}=89.2$ vs $\mathrm{M}=$ $48.5, \mathrm{p}<.01)$, Day $2(\mathrm{M}=130.8$ vs $\mathrm{M}$ $=63.6, \mathrm{p}<.001)$, and Day $3(\mathrm{M}=$ 143.2 vs $49.1, p<.001)$. In accord with earlier experiments, frequency did not have a reliable effect upon the total number of barpresses, and did not interact significantly with termination or days.

\section{EXPERIMENT 7}

It was demonstrated in Experiment 6 that a group of Ss made more barpresses when the response produced 10-sec terminations of vibration than did a group of Ss which received continuous vibration. The aim of Experiment 7 was to demonstrate the importance of vibration termination in the context of a within-S design. This aim was implemented in a two-bar choice paradigm.

The Ss were 12 female Holtzman albino rats, body weight $M=260.4 \mathrm{~g}$, range $246.2-276.9 \mathrm{~g}$. The $\mathrm{Ss}$ had previously been in a runway experiment.

Apparatus
The vibration apparatus was further modified by the addition of a second Gerbrands lever, which was located on the wall opposite to the original lever. Procedure

During every $20-\mathrm{min}$ test, pressing one lever terminated the vibration for $10 \mathrm{sec}$, pressing the opposite lever did not. The location of the termination bar was counterbalanced and the Ss were assigned randomly and equally to the two treatments, i.e., termination bar on the left and nontermination bar on the right, and vice versa. Each $\mathbf{S}$ received $20-\mathrm{min}$ daily tests for 3 days. Then the location of the termination and no-termination bars were reversed and the Ss had 20-min daily tests for 3 more days. All tests were conducted under $8-\mathrm{Hz}$ vibration with the amplifier power set at $2.0 \mathrm{~A}$, producing an amplitude of $\sim 0.24 \mathrm{in}$., peak-to-peak. Responses to both bars were recorded on digital counters.

\section{Results}

The percentages of responses to the termination bar on Days 1,2 , and 3 we re $79.6,88.2$, and 91.3, respectively. On Day 1,11 out of 12 Ss made more total responses on the termination bar than they did on the nontermination bar $(\mathrm{p}=.01)$, and on Days 2 and 3,12 out of $12 \mathrm{Ss}$ preferred the termination bar $(p=.001)$. When the locations of the termination and nontermination bars were reversed, the percentages of responses to the termination bar on Days 1,2 , and 3 of reversal were 52.4 , 80.9 , and 85.9 , respectively. On Day 1,5 out of 12 Ss responded more frequently to the termination bar (p > .05), and on Days 2 and 3,12 out of 12 Ss preferred the termination bar $(p=.001)$. Thus, when offered a choice between a bar which briefly terminates low-frequency whole-body vibration and one which does not terminate vibration, rats quickly develop a clear preference for the termination bar; when the location of the bars is reversed, the rats again quickly manifest a preference for the terminating bar.

\section{DISCUSSION}

Experiment 4 demonstrated the importance of the amplitude of vibration in escape conditioning: A direct relationship was evident between amplitude and the number of escape responses when frequency was held constant and amplitude was varied. In contrast to amplitude, the frequency of vibration within the limits of 8 to $22 \mathrm{~Hz}$ which were imposed was not found to be related to the number of escape responses in either the first three investigations or in Experiment 6.

Experiment 5 suggested that the escape conditioning observed with vibration cannot be explained in terms of the noise produced by vibration. The Ss without vibration but with the noise of vibration and its termination following barpressing and Ss without noise or vibration both performed at the baseline of Ss without vibration.

Experiments 6 and 7 demonstrated that the escape conditioning under vibration cannot be accounted for in terms of the activating effect of vibration. The importance of termination of vibration in such escape conditioning was shown in the context of both a between-S experimental design (Experiment 6 ) and a within-S paradigm (Experiment 7 ). It should be noted, however, that activation is not unimportant; the Ss with continuous vibration and no termination did display a considerable number of barpresses. We would anticipate that rats exposed to continuous shock in a Skinner box would likewise emit a considerable number of barpresses, but we are unaware of any studies employing this arrangement of shock.

This series of studies suggests that low-frequency whole-body vibration of sufficient amplitude is aversive for rats and that its brief termination is reinforcing. Since rats respond to vibration much as they do to low-intensity shock, vibration would appear to be a viable alternative source for aversive stimulation. The case for the aversiveness of vibration will be strengthened if it is possible to demonstrate avoidance conditioning mediated by vibration. Everyday observations on the effects of vibrators applied locally indicate that vibration is not always aversive. Further studies are in progress to test the role of vibration in avoidance conditioning and to determine at what parameters vibration onset becomes a positive reinforcer. 


\section{REFERENCES}

HUNT, J. M. \& QUAY, H. C. Early vibratory experience and the question of innate reinforcement value of vibration and other stimuli: A limitation on the discrepancy (burnt soup) principle in motivation. Psychological Review, 1961, 68. 149-156.

MYERS. J. L. Fundamentals of experimental design. Boston: Allyn \& Bacon, 1966.

SCHAEFER. V. H., LING. H. J., FARRAR, J. U., \& WEINS. D. Lethality in rats as a function of frequency in constant-displacement vibration. USA Medical Research Laboratory Report. 1959 , No. 390

SCHAEFER, V. H.. ULMER, R. G., \& LINK, H. J. Some behavioral and physiological studies in vibration. USA Medical Research Laboratory Report. 1959, No. 389

SOSKIN, R. A. The effects of early experience upon the formation of environmental preferences in rats. Journal of Comparative \& Physiological Psychology, 1963, 56, 303-306.

WIKE, E. L. Dato analysis: A statistical primer for psychology students. Chicago: Aldine-Atherton, 1971.

\section{NOTES}

1. Hunt, J. M. Personal communication. May 6, 1971.

2. This transformation was performed to maximize the $F$ ratio for treatments and minimize interaction in accord with Myers' (1966) suggestion for a Latin-square design.

3. If the time-out responses had been included, the results would have been more significant, since termination and time-out responses are positively correlated. 